\title{
On the Evolution of Mobile Platform Ecosystem Structure and Strategy
}

The mobile ecosystem is experiencing a wave of transformation with the emergence of new players, changing roles of existing players, and the creation of new business models. Drivers of change include attractive consumer tariffs for ubiquitously available mobile broadband access, development of increasingly powerful mobile devices, and the emergence of an "App Economy". Mobile platforms play a particularly central role in this transformation. Drawing on theories of technological platforms and business ecosystems a visualization approach to the study of mobile platform ecosystem structure and strategy is presented. The study provides a basis for understanding change in the converging mobile ecosystem.

DOI 10.1007/s12599-011-0174-4

\section{The Authors}

Rahul C. Basole, Ph.D. ( $\varangle)$

Georgia Institute of Technology

Tennenbaum Institute

760 Spring Street NW

Atlanta, GA 30332

USA

rahul.basole@ti.gatech.edu

\section{Dr. Jürgen Karla}

Institute of Business Information

Systems

RWTH Aachen

Templergraben 64

52062 Aachen

Germany

karla@winfor.rwth-aachen.de

Received: 2010-08-30

Accepted: 2011-07-11

Accepted after three revisions

by Dr. Bub.

Published online: 2011-08-30

This article is also available in German in print and via http://www. wirtschaftsinformatik.de: Basole RC, Karla J (2011) Entwicklung von Mobile-Platform-Ecosystem-Strukturen und -Strategien. WIRTSCHAFTSINFORMATIK. doi: 10.1007/s11576-0110286-y.

(C) Gabler Verlag 2011

\section{Introduction}

In recent years global handset sales have been primarily driven by the significant growth of smartphones, a type of mobile device that uses a high-level operating system (OS), or mobile platform, to run a wide variety of applications which are downloaded and installed by users. The success of smartphones has in turn led to an intense battle between mobile platform providers, each looking for ways to become the system of choice for mobile device manufacturers, mobile network operators, and mobile application developers (Calem 2010, p. 18). Unquestionably, the outcomes of this platform battle will shape the future of the mobile industry as it will either accelerate or stifle innovation and growth.

This paper uses a visualization approach to provide a deeper understanding of the evolving structure and strategies used in the mobile platform ecosystem over the past five years and its implications for the future. We focus our study on four key market segments, namely mobile device manufacturers (MDM), mobile network operators (MNO), mobile application developers (MAD), and mobile platform providers (MPP). The chosen context and timeframe is relevant for three key reasons. First, due to the enormous financial opportunities generated by smartphones, the mobile ecosystem is rapidly transforming and new relations and affiliations are continuously formed (Basole 2009, p. 147). Second, the four segments constitute the core of the evolving mobile ecosystem as they are fundamentally involved in the building, design, and distribution of handsets, software, hardware, and mobile networks associated with smartphones. Lastly, the chosen time span has seen a rapid rise in smartphones adoption and usage as well as the emergence of several new mobile platforms, such as Apple's iOS (formerly named Apple OS), Android, LiMo, and webOS (formerly named Palm OS). Any attempt to understand the future of mobile telecommunications will consequently require an understanding of the as-is and to-be of the mobile platform ecosystem.

\section{Theoretical Foundation}

Our study of the evolution of the mobile platform ecosystem builds on several complementary theoretical foundations. A complete review of the literature is beyond the scope of this paper. Table 1 presents a summary of relevant research streams and key studies. In the following section we elaborate in further detail on the particular importance of platforms, the strategic and economic relevance of interfirm networks, and the application of structural analysis and visualization to the study of business ecosystems.

\subsection{Technology Platforms}

The value, design, and management of technology platforms has been a topic of increasing interest to both researchers and practitioners (see Table 1). Armstrong (2006, p. 668) and Rochet and Ti- 
Table 1 Summary of Relevant Literature

\begin{tabular}{|c|c|c|}
\hline Research Stream & Description & Supporting Literature \\
\hline Business ecosystem & $\begin{array}{l}\text { - Study of economic communities consisting of interacting } \\
\text { organizations. } \\
\text { - Concept is based on the ecological metaphor that firms are } \\
\text { part of a larger ecosystem, each occupying a contributing } \\
\text { role and forming symbiotic relationships with customers, } \\
\text { suppliers, and competitors. }\end{array}$ & $\begin{array}{l}\text { Moore (1993, 1996), Iansiti and Levien (2004a, } \\
\text { 2004b), Iyer et al. (2006), Chesbrough and } \\
\text { Appleyard (2007) }\end{array}$ \\
\hline Interfirm networks & $\begin{array}{l}\text { - Study of the formation, evolution, governance, } \\
\text { transformation, and consequences of different types of } \\
\text { interfirm networks (e.g., strategic, innovation, R\&D, } \\
\text { supply, licensing, consortia, etc.). } \\
\text { - Studies assume one of two complementary levels of } \\
\text { analysis: actor level or whole network level. } \\
\text { - Common themes include relationships, connectedness, } \\
\text { embeddedness, social capital, collaboration, trust, } \\
\text { cooperation, and contracts. }\end{array}$ & $\begin{array}{l}\text { Oliver (1990), Galaskiewicz and Wasserman (1989), } \\
\text { Ahuja (2000), Dyer and Singh (1998), Gnyawali and } \\
\text { Madhavan (2001), Gulati (1998), Gulati et al. (2000), } \\
\text { Nohria and Garcia-Pont (1991), Gulati and Gargiulo } \\
\text { (1999), Venkatraman and Lee (2004), Koka and } \\
\text { Prescott (2008), Provan et al. (2007), Schilling and } \\
\text { Phelps (2007), Rosenkopf and Schilling (2007) }\end{array}$ \\
\hline Technology platforms & $\begin{array}{l}\text { - Study of the purpose, design, economics (e.g., pricing, } \\
\text { incentives, network externalities, etc.), and role of } \\
\text { proprietary or open source technology platforms. }\end{array}$ & $\begin{array}{l}\text { Gawer and Cusumano (2002), Rochet and Tirole } \\
\text { (2003), West (2003), Economides and Katsamakas } \\
\text { (2006), Brousseau and Penard (2007), Eisenmann } \\
\text { (2008), Evans et al. (2006) }\end{array}$ \\
\hline Network visualization & $\begin{array}{l}\text { - Study of the visualization and navigation of abstract data } \\
\text { structures for purposes of exploration, discovery, and } \\
\text { sense-making. } \\
\text { - Human-computer interaction issues play a central role. } \\
\text { - Common topics include graph layouts, navigation and } \\
\text { interaction, clustering, and system development. }\end{array}$ & $\begin{array}{l}\text { Tufte (1983), Becker et al. (1995), Eick (1996), Abello } \\
\text { et al. (1999), Di Battista et al. (1999), Herman et al. } \\
\text { (2000), Ware et al. (2002), Moody et al. (2005), } \\
\text { Keller et al. (2006), Shneiderman and Aris (2006) }\end{array}$ \\
\hline Mobile telecom industry & $\begin{array}{l}\text { - Study of a wide range of topics, including competition, } \\
\text { partnerships, innovation, evolution, policy, etc. }\end{array}$ & $\begin{array}{l}\text { Barnes (2002), Li and Whalley (2002), Maitland et al. } \\
\text { (2002), Peppard and Rylander (2006), Tilson and } \\
\text { Lyytinen (2006), Dittrich and Duysters (2007), } \\
\text { Rosenkopf and Padula (2008), Basole (2009), Reuver } \\
\text { et al. (2009) }\end{array}$ \\
\hline
\end{tabular}

role (2003, pp. 3-4) suggested that technology platforms are multi-sided markets since they bring together various types of participants, or sides, such as buyers and sellers. Studies have used various lenses to understand platform competition (Rochet and Tirole 2003), emergence (Iyer et al. 2007), strategies (West 2003), strategic differences (Economides and Katsamakas 2006), and the role of complementary markets (Gawer and Henderson 2007). Gawer and Henderson (2007, p. 1) suggest that many high-tech products and services can be considered as "systems of interdependent components, built around and on top of platforms" and are often provided by a complex network of firms, or ecosystem (Iansiti and Levien 2004a, p. 17). Technology platforms provide other constituents the ability to build and provide complementary products and services (Parker and Alstyne 2008, p. 2).

\subsection{Interfirm Networks and Business Ecosystems}

The conceptualization of markets as ecosystems is a result of theoretical extensions of work in interfirm networks, alliances, and innovation (Basole and Rouse 2008, p. 55). In her seminal work, Oliver (1990) suggested that interfirm relations are a result of six fundamental determinants, namely asymmetry, reciprocity, efficiency, stability, legitimacy, and necessity. In emerging technology industries, networks and alliances were found particularly beneficial due to the ability for firms to share risks, to develop, and to have access to synergistic knowledge (Eisenhardt and Schoonhoven 1996, p. 136).

Recent studies have adopted a complex networked systems perspective to examine why, when, and how interfirm networks and alliances form and change (Gulati et al. 2000). This view combines both the resource-dependency and embeddedness perspective and suggests that interfirm networks are complex systems characterized by co-evolving actors engaged in collaboration and competition (Iansiti and Levien 2004a, p. 41). The complex networked systems approach we apply has been used to study value networks and ecosystems in a variety of industries (Basole 2009; Basole and Rouse 2008; Rosenkopf and Schilling 2007).

\subsection{Structural Analysis and Visualization}

Given the importance of interfirm relations in the technology platform context, it is valuable to gain a greater understanding of the underlying structural characteristics of different platform ecosystems and the resulting business model implications. Broadly, an ecosystem can be described as a networked system that contains a set of objects (e.g., actors, nodes, etc.) that are tied to each other. In 
Table 2 Summary of Platform Ecosystem Elements

\begin{tabular}{ll}
\hline Element & Description \\
\hline Vertex (Node) & Actor (Firm), Player, Entity in the Platform Ecosystem \\
- Label & Actor Name (e.g., Symbian, Google, Nokia, T-Mobile, Vodafone) \\
- Type & Type or Class of a Firm (e.g., Supplier, Partner, Competitor) \\
- Attributes & $\begin{array}{l}\text { Segment (e.g., Device Manufacturer, Silicon Vendor, Network Operator), } \\
\text { Company Size, Company Revenue, Geospatial Position (e.g., Country, }\end{array}$ \\
& Location) \\
Edge (Link) & $\begin{array}{l}\text { Tie, Connection, Relationship } \\
\text { - Attributes }\end{array}$ \\
& $\begin{array}{l}\text { Strength of Relation, type of Relation, Length of Relation, Type of Value } \\
\text { Exchanged (e.g., Knowledge, Money, Material, Product, Service) }\end{array}$ \\
- Direction & Directed (e.g., flow from source to destination node), Undirected \\
\hline
\end{tabular}

platform ecosystems, these objects tend to be firms, and ties are often buyersupplier relationships, alliances, or partnerships. Depending on the relationship, ties can be directional, indicating an origin and destination, or non-directional. The conceptualization of ecosystems as a combination of objects and ties is particularly useful as researchers can base their model and hypotheses testing on the established mathematical field of graph theory. While an analytical approach provides valuable insights into the structure and dynamics of ecosystems, important knowledge can also be gained through the visualization of complex network data (Basole et al. 2010, pp. 1-2).

Visualization of complex systems, however, is not only a very challenging and difficult task but also, if not developed, implemented, or applied correctly, may lead to non-conclusive results (Tufte 1983). Particularly in visualizing complex interfirm networks or ecosystems, node-link configurations are not necessarily unique, and results may be misleading. The boundary-setting problem, or inclusion of nodes, is often artificial. Conclusions based on these models must thus be carefully scrutinized for the possibility of alternative explanations. Along the same lines, the amount of information that is captured and presented can often be overwhelming to the end-user. In many instances, what complex network data are and how they are visualized depends not only on the nature of the data but also on the question that is being asked and ultimately the cognitive abilities of the user. In order to overcome the aforementioned challenges, researchers must therefore ensure a balance between detail, abstraction, accuracy, efficiency, perceptual tension, and aesthet- ics in their complex network visualizations. These observations highlight the importance of setting the context and defining the elements in an ecosystem visualization study very carefully. Table 2 provides a non-exhaustive summary of relevant network elements and their attributes that should be considered when visualizing platform ecosystems.

\section{The Mobile Platform Ecosystem}

Prior to our structural analysis and visualization, it is important to have an understanding of the overall context of our study. The mobile business market is highly dynamic particularly due to continuous technological advances. The enormous market opportunities have led to an entry of a multitude of new participants, while other participants had to re-position themselves. In other instances, firms have extended their activities to neighboring value chain stages. This phenomenon was particularly observable in the case of MNOs which, owing to their unique market position, were able to actively participate in areas other than that of their core business, e.g., as portal providers, content providers, and MADs. The conceptualization of the mobile business market as a linear, one dimensional supply chain process is therefore inadequate and has led to study these contexts as value networks ( $\mathrm{Li}$ and Whalley 2002, p. 462; Peppard and Rylander 2006, p. 14). The mobile industry has consequently been described as a complex system with numerous inter-firm relationships across multiple segments (Basole 2009; Rosenkopf and Padula 2008).

The success of smartphones has led to a virtual battle of mobile platforms in the mobile ecosystem. There are over
40-50 different mobile platforms, but seven of them hold approximately 97\% of the entire market (Nielsen 2010). Key players include Symbian, Windows Mobile, BlackBerry, webOS, multiple variants of Linux-based platforms, and more recently Apple's iOS and Google's Android.

The exponential development of mobile data service usage derives in part from the introduction of new devices and innovative concepts - in particular those of mobile platform ecosystems. It was Apple who triggered this development when they introduced the iPhone in 2007 which was tightly integrated with its iTunes software and has since become a commercial and cultural phenomenon. The success factor thus was not only the device, but also a tightly integrated system that enabled simple application downloads, management, and payments called the App Store. The success of Apple's App Store concept stimulated other device manufacturers to develop their own platform ecosystems as discussed later. Since the introduction in 2007, developments have been quite remarkable: whereas MNOs have been losing their control and influence on the mobile ecosystem, MPPs and MADs have significantly enhanced theirs.

The emergence of app stores significantly impacted MADs. Prior to app stores, market access for MADs was quite limited; MADs generally had to enter contracts with MNOs to have their application included in the MNO's portal, the traditional application access channel for mobile users. MNO portals that once dominated content distribution are now paling in significance compared to app stores (Parton et al. 2011, p. 28). While users also had the possibility to directly downloading an application from the developer's website, this option was rarely utilized. Transaction costs were simply too high. The introduction of integrated app stores fundamentally changed the rules of the game. MADs can now submit their products to two-sided electronic markets (Brousseau and Penard 2007, p. 90), benefiting from lowered market entrance barriers such as reduced search costs and payment process handling. This has led to massive entry of many small and medium sized software firms as well as an enormous number of individual developers. Table 3 provides an overview of the development of the total number of apps and active MADs for each mobile 
Table 3 Major App store characteristics (Distimo 2011)

\begin{tabular}{|c|c|c|c|c|c|c|}
\hline & \multicolumn{2}{|l|}{2009} & \multicolumn{2}{|l|}{2010} & \multicolumn{2}{|l|}{$2011^{\mathrm{c}}$} \\
\hline & Apps & $\overline{\text { Developers }}$ & $\overline{\text { Apps }}$ & $\overline{\text { Developers }}$ & Apps & $\overline{\text { Developers }}$ \\
\hline Apple App Store ${ }^{\mathrm{a}}$ & 126,206 & 28,152 & 306,815 & 65,919 & 342,141 & 75,850 \\
\hline BlackBerry App World & 4,412 & 1,110 & 17,923 & 2,660 & 27,029 & 3,927 \\
\hline Google Android Market & 17,966 & 5,177 & 149,214 & 27,811 & 217,155 & 41,000 \\
\hline Nokia Ovi Store & 6,556 & 638 & 25,150 & 3,396 & 31,023 & 4,642 \\
\hline Palm App Catalog & 1,899 & 612 & 5,191 & 1,124 & 6,398 & 1,229 \\
\hline Windows Marketplace ${ }^{\mathrm{b}}$ & 873 & 357 & 6,779 & 3,068 & 13,522 & 5,170 \\
\hline
\end{tabular}

aiPhone apps only (excludes Mac Apps and iPad apps)

${ }^{\mathrm{b}}$ Includes apps and developers for Windows Phone 7

${ }^{c} \mathrm{Q} 1$ data only

platform application store from 20092011. Two points of caution should be noted when evaluating the growth: first, while large active MADs exist, many active MADs submit only a small number of applications, in many instances only a single application to a particular app store. Second, a multiple mobile platform development approach has only recently emerged.

\section{Method}

The aim of this paper is an analysis and visualization of the structure and evolution of the mobile platform ecosystem to identify structural configurations that characterize various types of business strategies and discuss both theoretical and practical implications.

\subsection{Data}

This study uses a unique dataset that was built by integrating two well-established primary data sources, (1) Thomson's Financial SDC Platinum database, a source commonly used in the study of interfirm networks (e.g., Schilling and Phelps 2007; Rosenkopf and Padula 2008; Lee et al. 2010), and (2) Connexiti database, which captures global supplier information from public filings, company publications, annual reports, major news feeds, and financial databases (e.g., Basole 2009). The dataset was seeded through the identification of companies listed in the recently launched NASDAQ OMX ${ }^{\circledR}$ CEA $^{\circledR}$ Smartphone Index (“QFON"), member companies participating in open platform foundations and leading companies in the mobile industry as provided by Fortune 1000 lists for 2006-2010.
Our visualization focuses on three of the four core segments of the mobile platform ecosystem: MDMs, MNOs, and MPPs. We did not include MADs in the visualization for three reasons. First, a comprehensive set of MAD segment data (e.g., apps and developers) is available only in aggregate form and from 2008 onwards (see Table 3). Second, an inclusion of all MADs would have unnecessarily reduced the clarity of our platform ecosystem visualization. Lastly, even with the availability of detailed MAD segment data, inclusion criteria are not obvious: the majority of key MADs are not large firms (as is the case with the other segments), but rather individual developers (e.g., Constantinou et al. 2010, p. 35; Parton et al. 2011, pp. 23-24). Both MDM (33422) and MNO (513322) map exactly to one NAICS code as provided by Thomson Corporation's Gale Company Profiles and Datamonitor. Given the very large number of actors, the study applied several company inclusion criteria: all leading MPP vendors were included; MNOs (>10 million subscribers) that offer high-speed data network services; and all leading MDMs (98\% market share) (Milanesi et al. 2009). Furthermore, it should be noted that we included both US and internationally based companies as an exclusion of any market would not adequately capture the truly global footprint of the mobile platform ecosystem.

The resulting dataset included 70 global companies and over 200 relationships. For each of these companies, the date they entered into a relationship (e.g., partnership announcement, product launch, etc.) with another actor in the platform ecosystem was identified using the Lexis-Nexis database; companyspecific data, such as size and financials, were also captured as provided by the D\&B Million Dollar and CompuStat database. We also obtained and cross-referenced global market share data for all MPPs from various Gartner and ComScore reports (e.g., De La Vergne et al. 2010; Milanesi et al. 2009). All data was collected and organized in a MySQL database for ease of manipulation and extraction.

\subsection{Visualization}

To visualize our interfirm network data, the study used Pajek (Version 1.26). Pajek is a general, non-commercial program for analysis and visualization of very large and complex networks (Batagelj and Mrvar 1998). Custom scripts were developed to automatically generate source code from the MySQL database for use in Pajek.

There are several network layout algorithms implemented in Pajek. For the purpose of this study, we used a combination of the Kamada-Kawai (KK) algorithm (Kamada and Kawai 1989) and Fruchterman-Reingold (FR) algorithm (Fruchterman and Reingold 1991). Both algorithms are force-directed algorithms. The KK algorithm is a multi-scale layout algorithm for the aesthetic drawing of undirected graphs with straight-line edges. It is based on the idea of optimizing a balanced spring system through energy minimization. Nodes that are close will pull on each other, while those that are distant will push one another apart. The algorithm seeks to find an optimum in which there is minimal stress on the springs connecting the whole set of nodes. The FR algorithm is similar to the KK algorithm but introduces a variable step width (or temperature) to ensure that the system reaches an equilibrium state. We chose to combine the two algorithms to generate a reasonable initial layout using the $\mathrm{KK}$ algorithm and then improve the positioning of neighboring nodes using the FR algorithm (Di Battista et al. 1999).

\subsection{Measurement of Network Properties}

The analysis of the ecosystem requires an understanding of the overall cohesion, position, and number of ties of the actors. We therefore use three network metrics for the structural analysis of mobile platform ecosystem evolution. These metrics are: network centralization, network density, and average degree of nodes (computed by segment type). Network centralization refers to the degree to which 
Table 4 Evolution of network characteristics

\begin{tabular}{llllll}
\hline & 2006 & 2007 & 2008 & 2009 & 2010 \\
\hline Platforms & 4 & 7 & 6 & 7 & 7 \\
Firms & 58 & 63 & 63 & 67 & 69 \\
Ties & 104 & 127 & 160 & 183 & 201 \\
Mobile Platform Providers & & & & & \\
- Mean Degree (S.D.) & 26.000 & $18.143^{*}$ & $22.857^{* *}$ & $22.875^{* *}$ & $25.125^{* *}$ \\
& $(16.990)$ & $(15.636)$ & $(14.736)$ & $(14.093)$ & $(14.994)$ \\
- min/max & $3 / 44$ & $3 / 44$ & $14 / 45$ & $4 / 45$ & $6 / 45$ \\
Mobile Network Operator & & & & & \\
- Mean Degree (S.D.) & 2.412 & $2.794^{* * *}$ & $3.588^{* * *}$ & $4.176^{* * *}$ & $4.500^{* * *}$ \\
& $(0.701)$ & $(0.946)$ & $(1.076)$ & $(1.314)$ & $(1.187)$ \\
- min/max & $1 / 4$ & $1 / 5$ & $1 / 6$ & $1 / 7$ & $2 / 7$ \\
Mobile Device Manufacturers & & & & & \\
- Mean Degree (S.D.) & 1.100 & $1.455^{*}$ & $1.652^{* *}$ & 1.577 & $1.714^{* *}$ \\
& $(0.308)$ & $(0.963)$ & $(0.982)$ & $(0.945)$ & $(0.976)$ \\
- min/max & $1 / 2$ & $1 / 4$ & $1 / 4$ & $1 / 4$ & $1 / 4$ \\
Density & 0.042 & 0.051 & 0.064 & 0.074 & 0.081 \\
Network Centralization & 0.6037 & 0.5942 & 0.5952 & 0.5857 & 0.5783 \\
\hline
\end{tabular}

Note: Significant difference from previous year $\left({ }^{*} p=0.1,{ }^{* *} p=0.05,{ }^{* * *} p=0.01\right)$; not applicable to 2006

the entire network is focused around a few central nodes (Scott 1991, pp. 8990). It can therefore be considered a measure of global centrality. Another global network measure is network density. Network density measures how sparse or dense a network is. It is measured using the proportion of ties in a network relative to the total number possible (Scott 1991, p. 71). A dense network thus indicates greater degree of interaction between actors in the ecosystem. The degree of a node refers to the number of connections a node has to other nodes (Iyer et al. 2006, p. 32). We distinguish the degree of a node by segment type.

\section{Results}

Table 4 presents the evolution of network characteristics of the mobile platform ecosystem between 2006 and 2010. The results show an increase in the number of leading mobile platforms from four in 2006 to seven in 2010, which includes the addition of iOS, Android, and webOS. While we find a modest growth in the number of complementary firms particularly with the entry of several new MDMs, such as Dell and Lenovo, the total number of ties between the firms in the mobile platform ecosystem nearly doubled in our five-year timespan. This tremendous growth may indicate both global growth of the industry as well as an increasing recognition for platform diversification and alliance value.

Our results further reveal a substantial variation over time in the number of platforms per MNO and per MDM. The average number of platforms per MNO increased from less than 2.5 in 2006 to 4.5 in 2010. A statistical means analysis reveals that there is a significant difference $(p<0.01)$ in the number of platforms per MNO from one year to the next. Similarly, we see a significant increase in the average number of platforms per MDM in every year, except 2009. The two other network metrics, density and centralization, show very little variation over time. However, the mobile platform ecosystem exhibits nearly $60 \%$ network centralization over the past five years indicating that the network is focused around a few platforms.

Figures 1a-1e show Pajek-generated visualizations of the mobile platform ecosystem from 2006 to 2010. Due to space constraints, we utilized Tufte's small multiples approach (Tufte 1983) to depict the structure of the mobile ecosystem for years 2006-2009. In Fig. 1e, 2010 MPPs, MDMs, and MNOs are depicted as nodes with $<$ bold $>$, <italic $>$, and $<$ normal $>$-type labels, respectively. The size of the MPP node indicates the global market share of that platform for that year. A link connects a firm to a platform if (i) a MDM sells a device with that platform or (ii) a MNO offers a device with that platform.

Several important observations can be made. First, while Symbian continues to be the leading platform, it has seen its market share shrink particularly due to the growth of iOS, BlackBerry, Windows Mobile, and more recently Android. This finding is supported by the fundamental slower growth of the number of active developers for the Symbian platform (Table 3). In contrast, iOS and Android in particular have seen their number of active developers surge dramatically. Another key observation across time is that several MDMs (e.g., Samsung, Motorola, and LG) provide devices with different platforms, suggesting a single leading platform has yet to emerge and multiple licenses exist.

Interesting is the relative position of Windows Mobile in the ecosystem, as it does not appear to play a central role in the mobile platform ecosystem at any point during our five-year span. A similar observation can be made for one of the Linux-based platforms, LiMo. With the recent introduction of the new Windows Phone 7 platform, however, we are observing a rapid growth of the number of active developers. It can also be observed that some of the larger MNOs (e.g., AT\&T, Vodafone, Orange, and TMobile) offer a greater number of platforms and devices.

Figure 1a shows the mobile platform ecosystem in 2006. Three distinct clusters can be identified; firms that are linked to Symbian, Windows Mobile, and BlackBerry. Symbian is the clear dominant mobile platform with nearly $75 \%$ of the total market. Virtually all major MDMs and MNOs use the Symbian platform. The next leading platform is Windows Mobile. It can be seen that there are several smaller MDMs that exclusively integrate the Windows Mobile platform into their product line.

Figure $\mathbf{1 b}$ shows the mobile platform ecosystem in 2007. This represents the year when Apple released the firstgeneration iPhone along with its iOS. Given the tremendous hype of the radical technological innovations and design of the iPhone, the iOS has had an immediate impact on the mobile device platform ecosystem. In 2007, two other platforms made their debut. One was Android, a platform supported by Google 


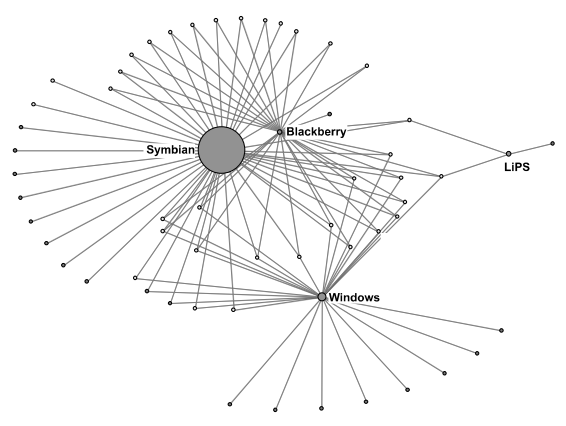

(a) 2006

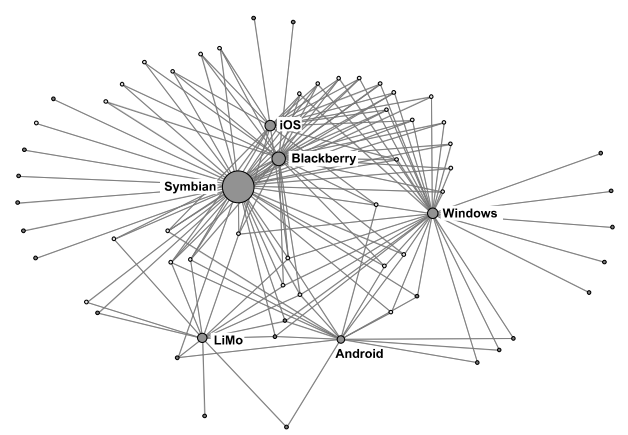

(c) 2008

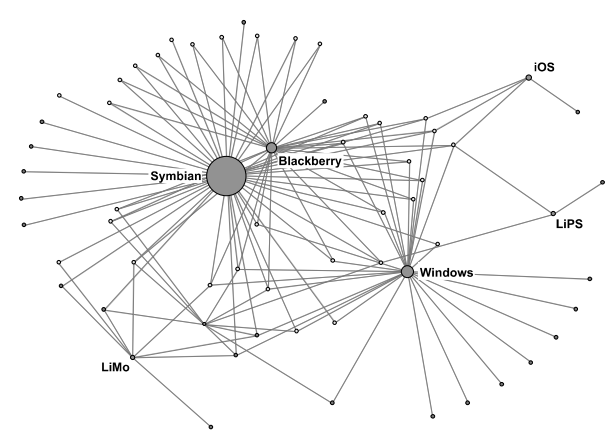

(b) 2007

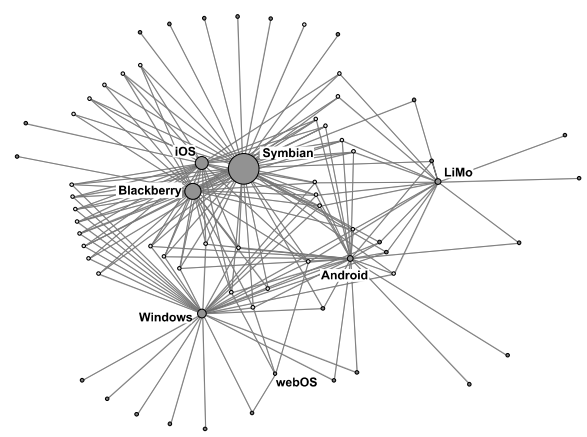

(d) 2009

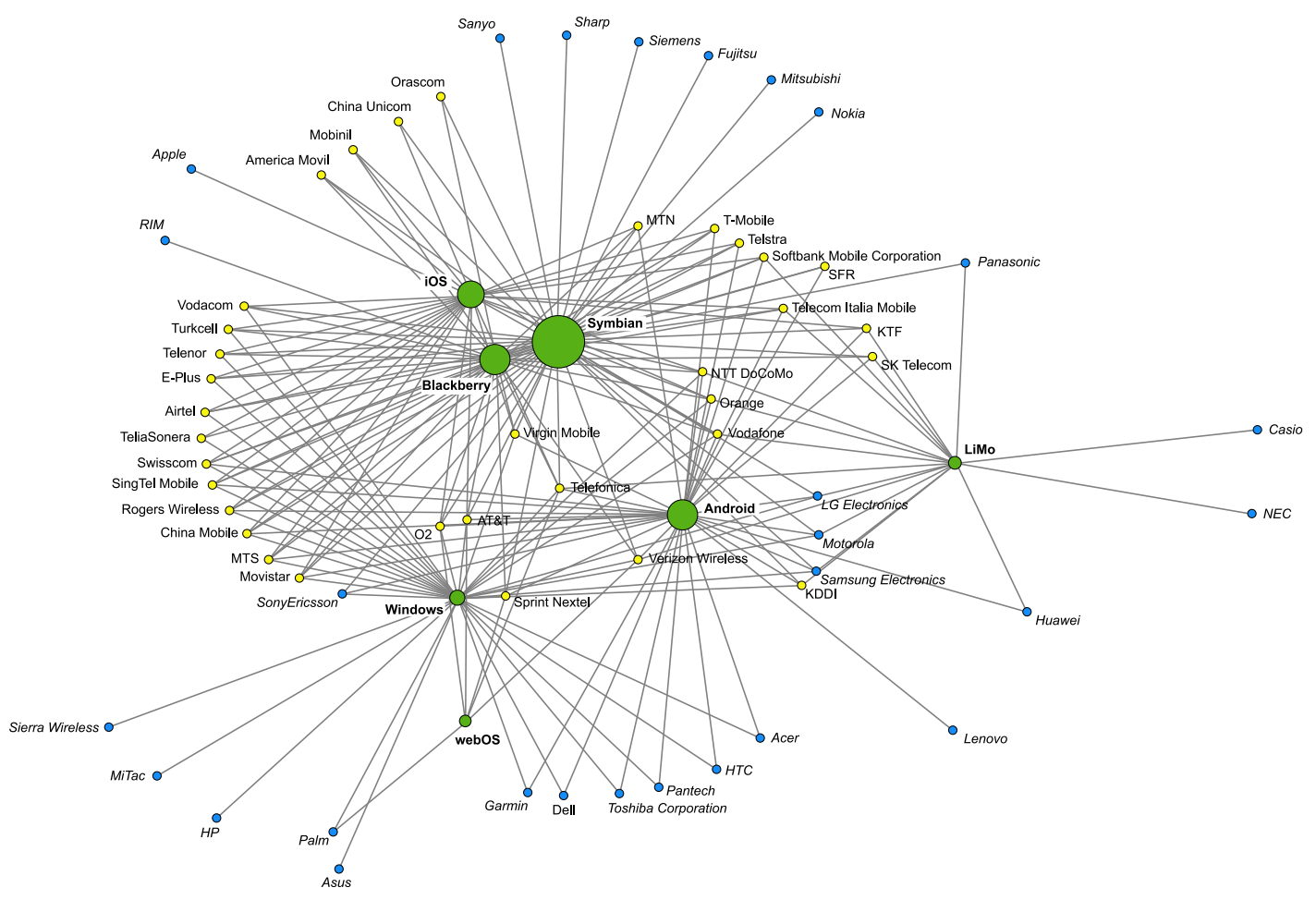

(e) 2010

Fig. 1 The evolution of the mobile platform ecosystem 
and endorsed by the Open Handset Alliance, a group of leading technology and mobile companies. The other platform was LiMo, a Linux-based platform supported primarily by technology and mobile companies from Europe and Asia, and some members of the Android platform.

One of the most striking changes in the mobile platform ecosystem in 2008 (Fig. 1c) is the rapid increase in ties Apple formed with MNOs. The visualization also shows that BlackBerry, Windows Mobile, and Android gained market share, while Symbian's platform leadership continued to decrease. In 2008, we also saw a consolidation in Linux platforms as LiPS announced to join the LiMo platform.

The mobile ecosystem in 2009 (Fig. 1d) saw a continued growth of iOS and Android, a significant decrease in Symbian, and a stagnation of BlackBerry, Windows Mobile, and LiMo market share. The visualization also shows the separation of the mobile platform ecosystem into four distinct MPP clusters, with iOS, BlackBerry, and Symbian occupying more central positions, Android and Windows Mobile placing on the inner ring and LiMo and the new entrant webOS clearly positioning at the periphery. In 2009, MADs clearly favored the iOS platform with Android coming in second.

Figure 1e shows the mobile platform ecosystem in 2010. Platform diversification among MNOs continues to grow, suggesting that a single dominant platform has not yet emerged. Both Windows Mobile and Symbian saw their market share decrease while BlackBerry remained relatively stable. One of the most interesting observations, however, is that Android leaped iOS in overall market share as a result of an increasing number of MDMs adopting it as their platform of choice and MNOs integrating it into their service offerings. Unquestionably, Android appears to have the largest momentum among all mobile platforms, although this is not clearly reflected in the number of active MADs. In 2010, iOS still held the top position with over 65,000 active MADs while the other platforms together were supported by less than 40,000 MADs. MAD segment data for 2011, however, suggests that Android will rapidly close the gap and perhaps even take the lead spot in the near future.

\section{Discussion}

The continuously evolving structure of the mobile platform ecosystem (see Fig. 1) has enormous strategic and economic implications for players in all market segments of the mobile industry. The rapid pace of market transformation as well as growing consumer demands have led to a closer collaboration of key mobile complementors as shown by the number of ties in Table 4. MPPs play a particularly critical brokering role in the converging mobile industry since they enable and drive the creation and delivery of new applications and content (Basole 2009, p. 156). Indeed, a mobile platform has the ability to lower the difficulty threshold of bringing content and applications to market, thus benefiting all players in the mobile ecosystem.

The fundamental reason for the rapid transformation of value creation and delivery in the mobile ecosystem has been the introduction of app stores which are tied to their respective platforms. App stores serve as electronic markets for digital goods and enable ecosystem participants to collaborate and offer their services for a particular platform. App stores tend to be the primary gateway for endusers to mobile applications and content. Consequently, platform app stores will play a critical role in the future development of the mobile business ecosystem.

With the app store concept, control over content and usage as well as over handling of payment processes for mobile data services no longer resides with MNOs but more with MPPs and to a certain extent MDMs (Suarez et al. 2009, pp. 2-10). In the past, mobile data usage was primarily driven through mobile portals of MNOs. However, as app stores have become more prolific, the role of MNOs changed. Although MNOs are trying to follow suit by offering their own app stores, they have yet to experience any notable success (Distimo 2010b). Our structural investigation supports this as evidenced by the less prominent, roles occupied by MNOs and the increasingly central positions of MPPs shown in Fig. 1. Our analysis also shows the close ties between MPPs and MDMs, which over the years have led to extensive value co-creation between the two segments.

With the emergence of multiple new platforms, however, the market has become increasingly fragmented with no real dominant standard. This "broken" ecosystem generates a myriad of challenges to e.g. MNOs, MDMs, and MADs. Possibly, it also poses a serious barrier to the growth of the entire mobile industry. Answers to questions such as: "What platform should developers develop for?" "What platform should MDM adopt?" and "Which platform provides MNOs the greatest increase in average revenue per user?" are of tremendous interest to all stakeholders. Similarly, users are often faced with the difficult decision which mobile device/platform combination to choose. While the user may not ultimately think about what platform they are using, they do care what applications are available, how they can get them, how much they cost, and how integrated the overall process is. Platforms have enabled MNOs and MDMs to differentiate their products and service offerings concerning different roles and different customer segments. In the past, MPPs often targeted a specific user segment. iOS and Android devices, for example, first were primarily used by consumers, whereas Blackberry focused on business professionals. Not surprisingly, the number of available applications per platform also differed (Table 3 ). With the recent surge in the consumer segment and growing recognition of the enormous enterprise mobility opportunity, however, virtually all MPPs are targeting both consumer and enterprise markets, leading to a blurring of the traditional platform segment foci. The goal of MPPs is therefore to become the preferred platform through collaborations and partnerships with its key enabling segments, MADs, MDMs and MNOs. In our structural analysis this goal translates to MPPs aiming to gain a more prominent position in the mobile ecosystem.

A case in point is the introduction of Apple's App Store in 2008. Other firms rapidly followed suit by offering similar solutions. After just one year, virtually all competitors had launched their own app store. However, platforms differ along several key technical and marketing characteristics, in particular its installed base, the number of apps, the number of active developers, the learning curve required for development, developer incentives, and last but certainly not least important revenue potential and revenue models (Distimo 2010a, 2010b). As a result, success has differed greatly across the different platforms. Recent data suggests that while the Apple App Store remains the largest app store, the Android 


\section{Abstract}

Rahul C. Basole, Jürgen Karla

\section{On the Evolution of Mobile Platform Ecosystem Structure and Strategy}

Platforms have become a core fundament of many technology industries. Platforms not only enable new products and services but have also been shown to influence strategies, shape business models, and even transform entire industries. Platforms play a particularly important role in the mobile ecosystem. The success of smartphones has led to an intense battle of mobile platforms, each looking for ways to become the system of choice for mobile device manufacturers, mobile network operators, and mobile application developers. Drawing on theories of platform markets, strategic networks, and business ecosystems, this paper uses a visualization approach to study the evolving global interfirm structure and examines strategies used in the mobile platform ecosystem over the past five years. We identify important differences between mobile platform strategies and discuss their implications for both mobile ecosystem participants and the future of the app economy.

Keywords: Mobile platform, Ecosystem, Visualization, Business model, Strategy, App economy
Market is the relatively fastest growing (Constantinou et al. 2010, p. 12, Table 2) which in turn supports our observation that Android appears to have the largest momentum. Android's growing prominence is evident in Fig. 1e. At the same time, the data presents only a proxy for the preferences and behavior of MADs. Indeed, iOS and Android are at the top of the list (Schwarzhoff 2010, p. 3).

Due to the proliferation of platforms and the popularity of mobile applications, people have begun to refer to this phenomenon as the "app economy" (Jeffries 2009; MacMillan et al. 2009; Edwards 2009). Indeed, with the rapid increase of people using mobile applications for everyday life as well as enterprise activities (Basole 2008, pp. 3), a corresponding development in supply and demand of mobile applications and services has been observed (Morgan Stanley Research 2009, pp. 133-134). In turn, this has led to many new opportunities for both MADs and content providers. Both segments have benefited from the platform concept given that in the past they only had very limited access to customers and mobile devices. The advent of mobile platforms eliminated this barrier. MPPs, on the other hand, utilized long tail effects (Anderson 2006, p. 53) to drive their platforms. The integration of mobile applications and mobile platforms therefore resulted in tremendous success for MPPs.

\section{Summary and Outlook}

Platforms have become a core feature of many emerging business models and are particularly important in the mobile industry. The success of a mobile platform is inextricably linked to its ecosystem. This study used a structural analysis and visualization lens to explore the interfirm relations in the mobile business sector with a focus on four key market segments, namely mobile device manufacturers (MDM), mobile network operators (MNO), mobile application developers (MAD) and mobile platform providers (MPP). In doing so, this study provides an important first step towards understanding the structure and dynamics of interfirm relationships in an emerging and rapidly changing domain, and makes several important contributions. First, the visual approach presented in this study provides insights into the structural evolution of interfirm relations. Second, it provides a comparison of incumbent and emerging platforms' competitive positions. Lastly, it identifies structural configurations that explain business strategies.

As any exploratory research, this study has some limitations. The accuracy of the visualization depends largely on the quality of the underlying data. While every precaution was taken to validate the completeness and accuracy of the data, it is possible that some firms and relations were not captured. At the same time, we also acknowledge that new platforms or platform versions will periodically emerge. For example, Microsoft recently released Windows Phone 7; unquestionably, the capabilities of this platform will alter the mobile platform landscape. Additionally, the recently shaped partnership between Nokia and Microsoft will also help to shift the prominence of both companies within the ecosystem. Our study also did not capture all relevant segments that may influence mobile platforms, such as mobile payment providers, for example. This simplification may have biased our results. Each of these limitations, however, represents an exciting area for future research.

Our study provides several avenues for future research. Visualization of business ecosystems is an area with tremendous research potential for the information systems, technology management and innovation research community. Future studies could include the comparison of different configurations of technology alliances and their impact on firm performance and innovation. An economic discussion of platform openness also seems promising. Similarly, visualization may help discover what structures and behaviors facilitate or inhibit growth of the platform ecosystems. Another opportunity for future research includes an examination of the role of mobile application developers in the mobile ecosystem. With very little standardization across platforms, developers must custom code their applications for use on multiple platforms. This is both cost and resource intensive and increases time-tomarket for applications.

\section{Acknowledgements}

The authors would like to thank the editors and four anonymous reviewers for their helpful comments and feedback. 
The authors would also like to thank Vincent Hoogsteder and Gert Jan Spriensma of Distimo B. V. for their insights on app store evolution and providing access to detailed data.

\section{References}

Abello J, Koutsofios E, Gansner E, North S (1999) Large networks present visualization challenges. ACM SIGGRAPH Computer Graphics 33:13-15

Ahuja G (2000) Collaboration networks, structural holes, and innovation: a longitudinal study. Administrative Science Quarterly 45(3):425-455

Anderson C (2006) The long tail: why the future of business is selling less of more. Hyperion, New York

Armstrong M (2006) Competition in twosided markets. The Rand Journal of Economics 37:668-691

Barnes SJ (2002) The mobile commerce value chain: analysis and future developments. International Journal of Information Management 22(2):91-108

Basole RC (2008) Enterprise mobility: applications, technologies, and strategies. IOS, Amsterdam

Basole RC (2009) Visualization of interfirm relations in a converging mobile ecosystem. Journal of Information Technology 24(2):144-159

Basole RC, Rouse WB (2008) Complexity of service value networks: conceptualization and empirical investigation. IBM Systems Journal 47(1):53-70

Basole RC, Hu M, Patel P, Stasko J (2010) Visualizing converging business ecosystems for competitive intelligence. In: Conference on Information Visualization, IEEE, Salt Lake City, pp 1-3

Batagelj V, Mrvar A (1998) Pajek - program for large network analysis. Connections 21(2):47-57

Becker RA, Eick SG, Wilks AR (1995) Visualizing network data. IEEE Transactions on Visualization and Computer Graphics 1:16-21

Brousseau E, Penard T (2007) The economics of digital business models: a framework for analyzing the economics of platforms. Review of Network Economics 6(2):81-114

Calem RE (2010) Battle of the handset operating systems. Vision, May/June: 18-21

Chesbrough HW, Appleyard MM (2007) Open innovation and strategy. California Management Review 50(1):57-76

Constantinou A, Camilleri E, Kapetanakis M (2010) Mobile developer economics 2010 and beyond. VisionMobile, London

De La Vergne HJ, Milanesi C, Cozza R, Gupta A, Lu CK, Nguyen TH, Zimmermann A (2010) Competitive landscape: mobile devices, worldwide, 2010. Gartner, Stamford

Di Battista G, Eades P, Tamassia R, Tollis IG (1999) Graph drawing: algorithms for the visualization of graphs. Prentice Hall, Upper Saddle River

Distimo (2010a) App stores - overview. http:// www.distimo.com/appstores. Accessed 2010-08-10

Distimo (2010b) Report - June 2010. http:// www.distimo.com/uploads/reports/ Distimo\%20Report\%20-\%20June\%202010. pdf. Accessed 2010-08-27

Distimo (2011) App store characteristics 2008-2011. Custom report (2011-05-24)
Dittrich K, Duysters G (2007) Networking as a means to strategy change: the case of open innovation in mobile telephony. Journal of Product Innovation Management 24(6):510-521

Dyer $J H$, Singh $H$ (1998) The relational view: cooperative strategy and sources of interorganizational competitive advantage. Academy of Management Review 23(4):660-679

Economides N, Katsamakas E (2006) Twosided competition of proprietary vs. open source technology platforms and the implications for the software industry. Management Science 52:1057-1071

Edwards C (2009) iMgonnagetrich. Engineering \& Technology 4(16):70-71

Eick SG (1996) Aspects of network visualization. IEEE Computer Graphics and Applications 16(2):69-71

Eisenhardt KM, Schoonhoven CB (1996) Resource-based view of strategic alliance formation: strategic and social effects in entrepreneurial firms. Organization Science 7(2):136-150

Eisenmann TR (2008) Managing proprietary and shared platforms. California Management Review 50(4):31-53

Evans DS, Hagiu A, Schmalensee R (2006) Invisible engines: how software platforms drive innovation and transform industries. MIT Press, Boston

Fruchterman TMJ, Reingold EM (1991) Graph drawing by force-directed placement. Software, Practice \& Experience 21(11):11291164

Galaskiewicz J, Wasserman S (1989) Mimetic and normative processes within an interorganizational field: an empirical test. Administrative Science Quarterly 34(3):454-479

Gawer A, Cusumano M (2002) Platform leadership: how Intel, Microsoft, and Cisco drive industry innovation. Harvard Business School Press, Boston

Gawer A, Henderson R (2007) Platform owner entry and innovation in complementary markets: evidence from Intel. Journal of Economics \& Management Strategy 16(1):1-34

Gulati R (1998) Alliances and networks. Strategic Management Journal 19(4):293-317

Gulati R, Gargiulo M (1999) Where do interorganizational networks come from? American Journal of Sociology 104(5):1439-1493

Gulati R, Nohria N, Zaheer A (2000) Strategic networks. Strategic Management Journal 21:203-215

Gnyawali DR, Madhavan R (2001) Cooperative networks and competitive dynamics: a structural embeddedness perspective Academy of Management Review 26:431445

Herman I, Melancon G, Marshall MS (2000) Graph visualization and navigation in information visualization: a survey. IEEE Transactions on Visualization and Computer Graphics 6(1):24-43

lansiti M, Levien R (2004a) The keystone advantage: what new dynamics of business ecosystems mean for strategy, innovation and sustainability. Harvard Business School Press, Boston

lansiti M, Levien R (2004b) Strategy as Ecology. Harvard Business Review 82(3):68-78

lyer B, Lee CH, Venkatraman N (2006) Managing in a 'small world ecosystem': lessons from the software sector. California Management Review 48(3):28-47

lyer B, Chi-Hyon L, Venkatraman N, Vesset D (2007) Monitoring platform emergence: guidelines from software networks. CAIS 19:1-13
Jeffries S (2009) The App economy. http:// www.guardian.co.uk/technology/2009/jul/ 29/iphone-apps. Accessed 2010-07-16

Kamada T, Kawai S (1989) An algorithm for drawing general undirected graphs. Information Processing Letters 31:7-15

Keller R, Eckert CM, Clarkson PJ (2006) Matrices or node-link diagrams: which visual representation is better for visualising connectivity models? Information Visualization 5(1):62-76

Koka BR, Prescott JE (2008) Designing alliance networks: the influence of network position, environmental change, and strategy on firm performance. Strategic Management Journal 29(6):639-661

Lee $\mathrm{CH}$, Venkatraman N, Tanriverdi H, lyer B (2010) Complementarity-based hypercompetition in the software industry: theory and empirical test, 1990-2002. Strategic Management Journal 31:1431-1456

Li F, Whalley J (2002) Deconstruction of the telecommunications industry: from value chains to value networks. Telecommunications Policy 26:451-472

MacMillan D, Burrows P, Ante SE (2009) Inside the app economy. Business Week 4153:347-357

Maitland CF, Bauer JM, Westerveld R (2002) The European market for mobile data: evolving value chains and industry structures. Telecommunications Policy 26(910):485-504

Milanesi C, Cozza R, Zimmermann A, De La Vergne HJ, Nguyen TH, Gupta A, Lu CK (2009) Competitive landscape: mobile devices, worldwide, 3Q09. Gartner, Stamford

Moody J, McFarland D, Bender-deMoll S (2005) Dynamic network visualization. American Journal of Sociology 110(4): 1206-1241

Moore JF (1993) Predators and prey: a new ecology of competition. Harvard Business Review 71(3):75-86

Moore JF (1996) The death of competition: leadership and strategy in the age of business ecosystems. Harper Collins, New York

Morgan Stanley Research (2009) The mobile Internet report. Morgan Stanley, New York

Nielsen (2010) U.S. smartphone battle heats up: which is the "most desired" operating system? http://blog.nielsen.com/ nielsenwire/online mobile/us-smartphonebattle-heats-up/. Accessed 2011-05-19

Nohria N, Garcia-Pont C (1991) Global strategic linkages and industry structure. Strategic Management Journal 12(1):105-124

Oliver C (1990) Determinants of interorganizational relationships: integration and future directions. Academy of Management Review 15:241-265

Parker G, Alstyne MV (2008) Managing platform ecosystems. In: Twenty ninth international conference on information systems. AIS, Paris, pp 1-13

Parton J, Kapetanakis M, Camilleri E, Constantinou A (2011) Developer economics 2011. VisonMobile, London

Peppard J, Rylander A (2006) From value chain to value network. European Management Journal 24(2):128-141

Provan KG, Fish A, Sydow J (2007) Interorganizational networks at the network level: a review of the empirical literature on whole networks. Journal of Management 33(3):479-516

Reuver MD, Bouwman H, Haaker T (2009) Mobile business models: organizational and financial design issues that matter. Electronic Markets 19(1):3-13

Rochet JC, Tirole J (2003) Platform competition in two-sided markets. Journal of the 
European Economic Association 1(4):9901029

Rosenkopf L, Padula G (2008) Investigating the microstructure of network evolution: alliance formation in the mobile communications industry. Organization Science 19(5):1-19

Rosenkopf L, Schilling M (2007) Comparing alliance network structure across industries: observations and explanations. Strategic Entrepreneurship Journal 1:191-209

Schilling MA, Phelps CC (2007) Interfirm collaboration networks: the impact of largescale network structure on firm innovation. Management Science 53(7):1113-1126
Schwarzhoff S (2010) Q2 mobile developer survey. Appcelerator, Mountain View

Scott J (1991) Social network analysis: a handbook. Sage, London

Shneiderman B, Aris A (2006) Network visualization by semantic substrates. IEEE Transactions on Visualization and Computer Graphics 12(5):733-740

Suarez F, Edelman B, Srinivasan A (2009) Symbian, Google \& Apple in the mobile space. Harvard Business School Case 909055, Boston

Tilson D, Lyytinen K (2006) The 3G transition: changes in the US wireless industry. Telecommunications Policy 30(1011):569-586
Tufte E (1983) The visual display of quantitative information. Graphics Press, Cheshire

Venkatraman N, Lee CH (2004) Preferential linkage and network evolution: a conceptual model and empirical test in the U.S. video game sector. Academy of Management Journal 47(6):876-892

Ware C, Purchase H, Colpoy L, McGill M (2002) Cognitive measurements of graph aesthetics. Information Visualization 1(2):103

West J (2003) How open is open enough? Melding proprietary and open source platform strategies. Research Policy 32(7): 1259-1285 